\title{
STANDARD FORTIFICATION (STD) VERSUS TARGET FORTIFICATION (TFO) IN VERY LOW BIRTHWEIGHT INFANTS: EFFECT ON GROWTH AND AMINO ACID PROFILE
}

\author{
C.M. Gebaver', B. Ackermann', J. Ristau', N. Stamm', M. Stopsack², W. Mihatsch³, U. Thome \\ ${ }^{1} 1$ Hospital of Children and Adolescents, Neonatology, Leipzig, Germany; ${ }^{2}$ Institut of Clinical Chemistry and Laboratory Medicine, \\ University Hospital Carl Gustav Carus, Dresden, Germany, ${ }^{3}$ Helios Klinik Pforzheim, Kinder- und Jugendmedizin, Pforzheim, Germany
}

Background: In human milk feeding fortification is required to prevent postnatal growth failure. Most fortifiers are made of bovine protein.

\begin{abstract}
Methods:
In a double-blind randomized controlled trial, VLBW infants 24-32 weeks of gestation (GA) were randomly assigned to either STD or TFO of an exclusively human milk diet from birth onwards to 36 weeks of corrected age (figure 1).

Inclusion criteria: gestational age 24.0-31.6 wks, birth weight 400-1499 g, minimum enteral intake $100 \mathrm{ml} / \mathrm{kg} / \mathrm{d}$ human milk

Exclusion criteria: congenital malformation, abdominal surgery, cholestasis, renal insufficiency, nutrition with formula

Each daily pooled 24 hour human milk feeding sample was analyzed by infrared spectroscopy (Miris, Uppsala, sweden). Standard fortification (STD) was performed by adding fixed amounts of multicomponent fortifier, protein powder and medium chain triglycerides. TFO was individually adjusted to achieve the following contents per $100 \mathrm{ml}: 3 \mathrm{~g}$ protein, $4.5 \mathrm{~g}$ fat. The primary study outcome was weight gain. Plasma amino acid concentrations at 36 wks of corrected GA were a secondary outcome. The following commercial products were used: Aptamil FMS (Milupa, Germany), Aptamil Eiweiß plus (Milupa, Germany) und MCT-oil (Ceres-Öl, Dr. Schär, Germany). Plasma amino acid levels (Analyzer B 30, Biochrom) were measured 2, 4 and 7 weeks after randomisation, serum urea levels every two weeks, urine urea levels weekly. Statistics: mean (SD), level of significance 0,05, SPSS 24 (Inc, Chicago, IL)
\end{abstract}

\section{Results:}

110 infants were enrolled, 109 were analyzed. There were no differences in demographic data, weight, length and head circumference at 36 wks of corrected GA (table 1). In the STD group protein intake was significantly higher whereas, fat and energy intake were significantly lower (table 2). There was no correlation between protein content and serum urea or plasma tyrosine levels or between serum urea and tyrosine levels (figure 2). Serum urea and plasma amino acid levels did not differ in both groups. Plasma amino acid levels were largely consistent with reference levels for preterms (Shapira et. al) (figure 3, 4). In 66 infants, tyrosine levels exceeded $200 \mu \mathrm{mol} / \mathrm{I}$ and 10 infants had levels above 500 $\mu \mathrm{mol} / \mathrm{l}$ (figure 5).
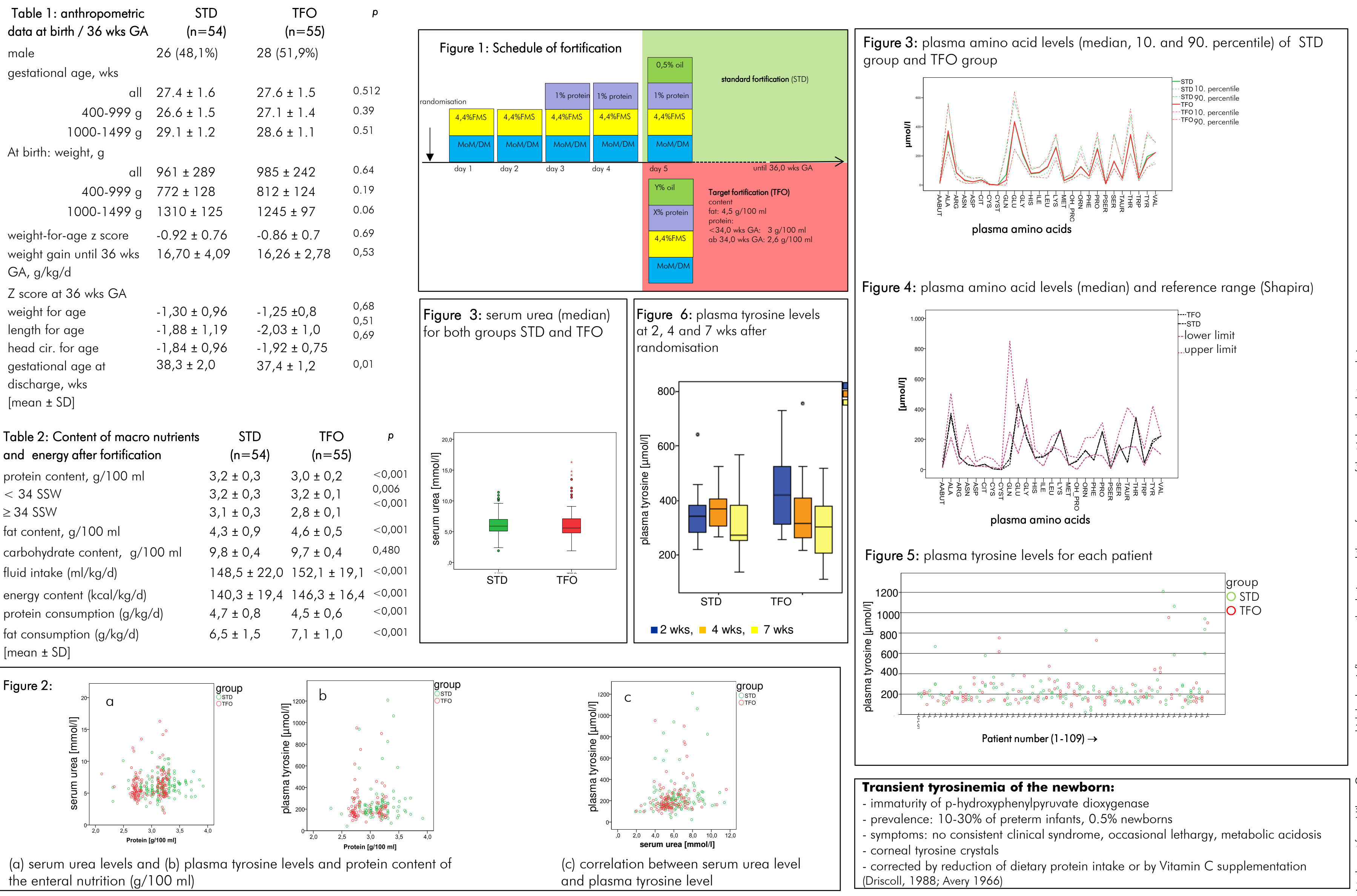

Conclusions: There was no difference between both groups in growth parameters at 36 weeks gestational age. During fortification according to recommended schemes for protein intake with either the standard or target regimen, plasma tyrosine levels above $500 \mu \mathrm{mol} / \mathrm{l}$ occurred. The high tyrosine levels could not be attributed to overfortification and are not indicated by increased serum urea levels. Should neonatologists monitor tyrosine levels routinely during fortification with extra protein? 